\title{
Requirements for Bend Insensitive Fiber in Millimeter-Wave Fronthaul Systems
}

Rommel, Simon; Cavalcante, Lucas Costa Pereira; Vegas Olmos, Juan José; Tafur Monroy, Idelfonso ; Mishra, Arvind K.

Published in:

2015 IEEE International Topical Meeting on Microwave Photonics

Link to article, DOI:

10.1109/MWP.2015.7356674

Publication date:

2015

Document Version

Peer reviewed version

Link back to DTU Orbit

Citation $(A P A)$ :

Rommel, S., Cavalcante, L. C. P., Vegas Olmos, J. J., Tafur Monroy, I., \& Mishra, A. K. (2015). Requirements for Bend Insensitive Fiber in Millimeter-Wave Fronthaul Systems. In 2015 IEEE International Topical Meeting on Microwave Photonics IEEE. https://doi.org/10.1109/MWP.2015.7356674

\section{General rights}

Copyright and moral rights for the publications made accessible in the public portal are retained by the authors and/or other copyright owners and it is a condition of accessing publications that users recognise and abide by the legal requirements associated with these rights.

- Users may download and print one copy of any publication from the public portal for the purpose of private study or research.

- You may not further distribute the material or use it for any profit-making activity or commercial gain

- You may freely distribute the URL identifying the publication in the public portal 


\section{Requirements for Bend Insensitive Fiber in Millimeter-Wave Fronthaul Systems}

\author{
Simon Rommel, Lucas Costa Pereira Cavalcante, \\ J. J. Vegas Olmos, Idelfonso Tafur Monroy \\ Department of Photonics Engineering \\ Technical University of Denmark \\ Kgs. Lyngby, 2800, Denmark \\ sirem@fotonik.dtu.dk
}

\author{
Arvind K. Mishra \\ Centre of Excellence \\ Sterlite Technologies Limited \\ E1-E3, MIDC, Waluj, Aurangabad, 431 136, India
}

\begin{abstract}
The impact of fiber bending on mm-wave radioover-fiber transmission is investigated and the need for bend insensitive fiber for front-haul installation confirmed. A $70 \mathrm{~m} \mathrm{~W}$ band hybrid photonic-wireless link including bend insensitive fiber is demonstrated with $B E R<10^{-6}$ at $5 \mathrm{~mm}$ bending radius.
\end{abstract}

\section{INTRODUCTION}

The increasing use of bandwidth intensive applications on mobile consumer devices such as smartphones and tablet computers has created a demand for high-speed wireless data communications at gigabit speeds that need to be supported by future $5 \mathrm{G}$ mobile networks. Millimeter-wave (mm-wave) radio-over-fiber (ROF) links have been identified as a key candidate for the required mobile front- and backhaul as well as direct gigabit-class wireless broadband services [1]-[5], as a viable alternative to baseband, digitized, packet encapsulated grey optic solutions [5], [6].

RoF links in the different mm-wave bands have been demonstrated with wireless transmission distances ranging from a few to multiple hundred meters and with a variety of optical generation, upconversion and radio-frequency (RF) detection setups [4], [7], [8]. The transmission fiber itself has received attention mostly with regard to transmission impairments due to dispersion and fiber nonlinearities [9] or the combination of single- and multi-mode fibers [7] andmore recently - as a means for capacity increase by combining spatial multiplexing in the fiber with the well known concept of multiple-input multiple-output (MIMO) RF transmission [3].

The practical consideration of on-premise fiber installation and optical wiring of - and within - the antenna has however been neglected, although it is obvious that-analogous to the case of fiber-to-the-x [10]-fiber bends with small radii are likely to occur. With the introduction of MIMO transmission and antenna arrays especially as well as their housing in compact, weather resistant and easy to mount outdoor units, radii well below $10 \mathrm{~mm}$ will be common and macrobending induced losses may thus play a significant role.

In this paper we assess the performance of a W-band RoF link with $15 \mathrm{~km}$ optical and $70 \mathrm{~m}$ wireless transmission. Significantly we include $5 \mathrm{~km}$ of bend insensitive fiber (BIF), we show that for radii below $15 \mathrm{~mm}$ BIF is a necessity and demonstrate how the use of different fibers from the set of specifications defined by ITU-T G.657 may allow different numbers of bends at different radii. Finally we discuss the trade-off between the available power budget, required tolerance to fiber bending and the cost of including BIF.

\section{EXPERIMENTAL SETUP}

The experimental setup is depicted in Fig. 1 and employs photonic upconversion at the transmitter, consisting of an external cavity laser (ECL) at $\lambda=1550 \mathrm{~nm}$ for signal generation, followed by a Mach-Zehnder modulator (MZM) driven with a sinusoidal at $f_{R F} / 2$ to generate two spectral lines spaced at $f_{R F}$. The signal is amplified and an arrayed waveguide grating (AWG) used to separate the two lines while suppressing the central line, allowing one line to be modulated in a second MZM. The latter is driven at data rates of $1 \mathrm{Gbit} / \mathrm{s}$ and $2.5 \mathrm{Gbit} / \mathrm{s}$ by a $2^{15}-1$ bit long pseudo-random bit sequence (PRBS15) non-return-to-zero (NRZ) signal from a pulse patter generator (PPG). The lines are recombined, amplified and transmitted through $10 \mathrm{~km}$ of ITU-T G.652 standard singlemode fiber (SMF) and one of three spool samples of $5 \mathrm{~km}$ Sterlite bending insensitive fiber. In order to test the effects of macrobending, the different fibers are wound for 1 to 10 turns around mandrels with radii between $5 \mathrm{~mm}$ and $15 \mathrm{~mm}$ while monitoring the resulting incident power on the photodiode (PD) with a $1 \%$ tap and recording bit-error rate (BER) values after wireless transmission. It should be noted that the impact of macrobending and the performance analysis of the BIF are independent of the choice of signal generation scheme.

The beating of the two signal lines on the PD generates the radio-frequency ( $\mathrm{RF}$ ) signal at $f_{R F}=84 \mathrm{GHz}$ which is transmitted wirelessly over a distance of $70 \mathrm{~m}$ with a pair of parabolic antennas-with a gain of $48 \mathrm{dBi}$ each. A low noise amplifier (LNA) with $40 \mathrm{~dB}$ gain restores the signal level before the receiver which consists of a Schottky diode based envelope detector (ED) and digital storage oscilloscope (DSO). With only a single LNA and the use of envelope detection rather than down-conversion with an electrical mixer the need for a local oscillator at the receiver is alleviated and the complexity in the RF domain is kept to a minimum. Finally BER values are determined through offline processing, consisting of simple thresholding and error counting over four recorded sequences with a combined length $>10$ Mbit.

Fig. 2 gives an overview of the laboratory setup with optical signal generation, bending test and receive antenna co-located 


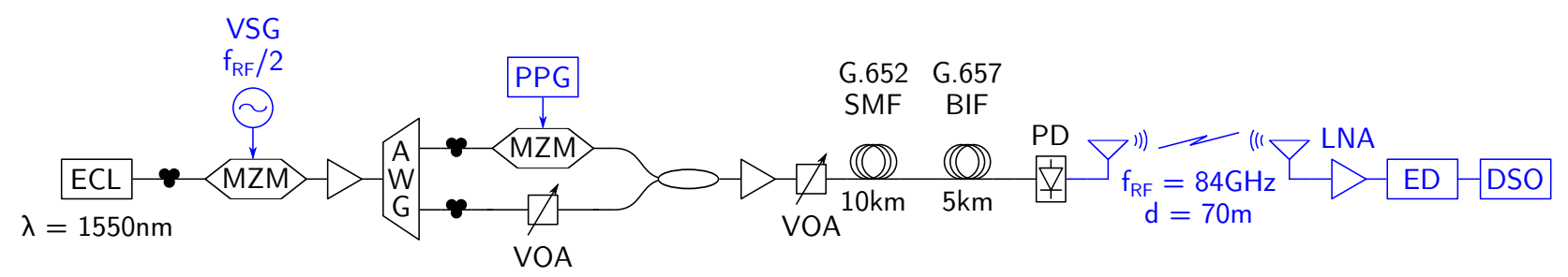

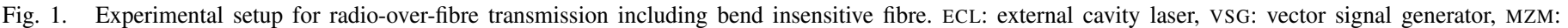

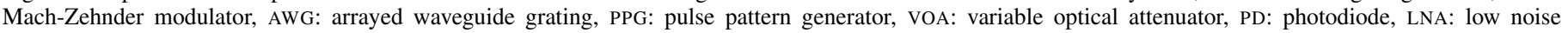
amplifier, ED: envelope detector, DSO: digital storage oscilloscope

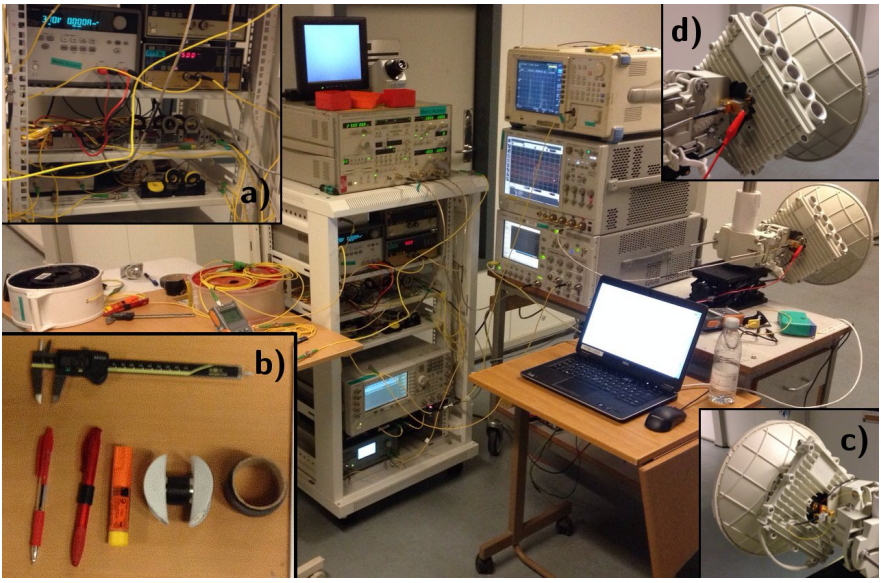

Fig. 2. Portable laboratory setup with photonic upconversion. Insets: a) Rackmounted optical setup, b) Mandrels of different radii, c) Transmit antenna with PD, d) Receive antenna with LNA and ED

for experiment convenience while the transmit antenna and attached PD are remotely fed through an optical fiber.

\section{EXPERIMENTAL RESULTS}

In this work the performance of a hybrid optical-wireless link is analyzed in the presence of fiber bends similar to what would be found in a fiber installation at a radio-access-unit or the antennae of a wireless broadband access link. First the macrobending loss performance of the different fibers under test is compared to the specification for bend insensitive fiber (BIF) of ITU-T G.657, with results shown in Fig. 3. The tested sample A shows marcobending losses significantly-as much as an order of magnitude at radii of $10 \mathrm{~mm}$ and $15 \mathrm{~mm}-$ below those of SMF and well below those required by ITU-T G.657.A1. Samples B and C show similar performance at a bending radius of $5 \mathrm{~mm}$ with sample $\mathrm{C}$ showing a five times lower loss at $7.5 \mathrm{~mm}$ radius; both show loss figures below the requirements set by G.657.A2/B2 and sample C further meets the loss requirements of G.657.B3.

As the number of bends in an installation may easily add up to the equivalent of five to ten turns, these loss figures indicate that while at a radius of $15 \mathrm{~mm}$ the bending loss introduced by SMF may be tolerable, category G.657.A1 fiber will be required at $10 \mathrm{~mm}$ and $\mathrm{A} 2 / \mathrm{B} 2$ or $\mathrm{B} 3$ fiber for even smaller radii in order to remain within typical system power budgets.

Fig. 4 a) and Fig. 5 a) show the dependency of system BER performance on the optical power $P_{P D}$ incident on the PD at $1 \mathrm{Gbit} / \mathrm{s}$ and $2.5 \mathrm{Gbit} / \mathrm{s}$ respectively. Setting $P_{P D}=6 \mathrm{dBm}$

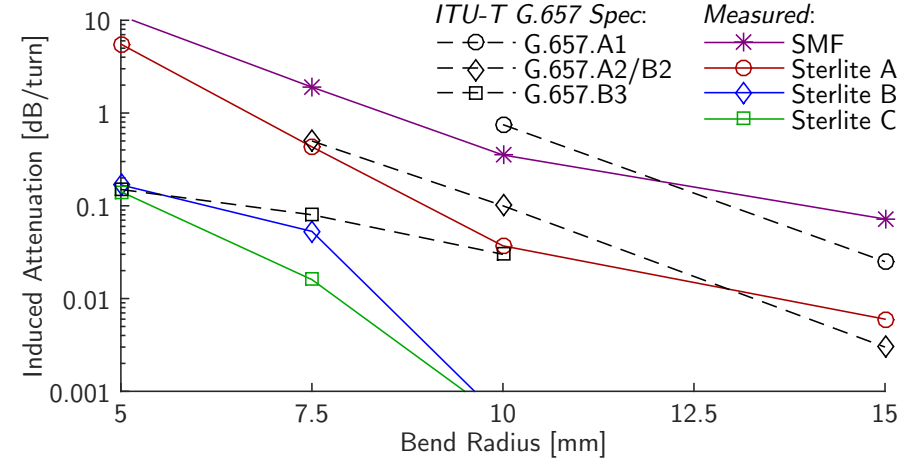

Fig. 3. Comparison of macrobending losses of Sterlite BIF fiber samples at $1550 \mathrm{~nm}$ with ITU-T G.657 A1, A/B2 and B3 specifications

as reference power and assuming a required maximum BER of $10^{-6}$ gives an allowable margin of just below $2 \mathrm{~dB}$ for loss induced by fiber bending, with a near negligible penalty for going from $1 \mathrm{Gbit} / \mathrm{s}$ to $2.5 \mathrm{Gbit} / \mathrm{s}$.

With the same BER limit and data rates the combinations of fibers, radii and numbers of turns that have been found to be allowable while maintaining system performance are shown in Fig. 4 b) and Fig. 5 b) respectively. ${ }^{1}$ The benefit obtained by the use of G.657 fibers is immediately visible at both data rates and it is evident that especially for small radii category A2/B2 and B3 fiber will be a necessity. The observed maximum allowable combinations together with the loss/turn values from Fig. 3 adhere to the allowable loss margin of about $2 \mathrm{~dB}$ derived from Fig. 4 a) and Fig. 5 a). While no difference between sample B and C fibers is observed in either Fig. 4 b) or Fig. 5 b), an extrapolation of the number of turns up to the found acceptable loss margin suggests respective allowable numbers of turns of 11 and 14 at $5 \mathrm{~mm}$ and 38 and 126 at $7.5 \mathrm{~mm}$, clearly showing the benefit of a fiber with bending loss as low as found for sample $\mathrm{C}$ when considering complex installations.

While the margin of $2 \mathrm{~dB}$ for allowable bending loss is specific to the assessed system and link, the trade-off it highlights is a general one, requiring assessment of system parameters such as the available power budget, logistical challenges such as the required tolerance to bending and ease of installation as well as economical considerations such as the additional cost of BIF. Due to the drastic differences in loss however these considerations are likely to be between the different types of

\footnotetext{
${ }^{1}$ Setting a BER limit of $10^{-3}$ does not significantly alter the picture with only a single data point being changed for each of the data rates as indicated by the $\nabla$ in Fig. 4 b) and $\triangle$ in Fig. 5 b).
} 

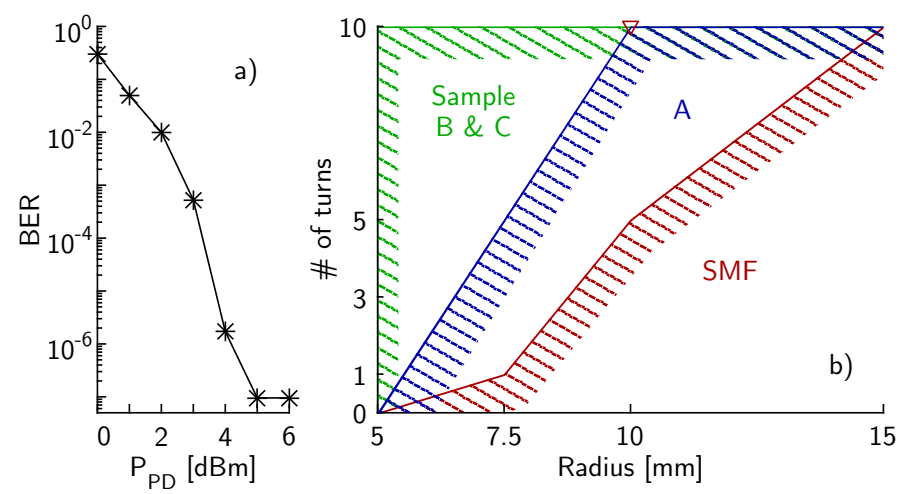

Fig. 4. a) BER vs $P_{P D}$ at $1 \mathrm{Gbit} / \mathrm{s}$ without bending, b) Allowable radii and numbers of turns for a system performance with BER $<10^{-6}$ at $2.5 \mathrm{Gbit} / \mathrm{s}$ $\left(\nabla: \mathrm{BER}=2.0 \cdot 10^{-4}\right.$ for 10 turns @ $10 \mathrm{~mm}$ with SMF fiber $)$
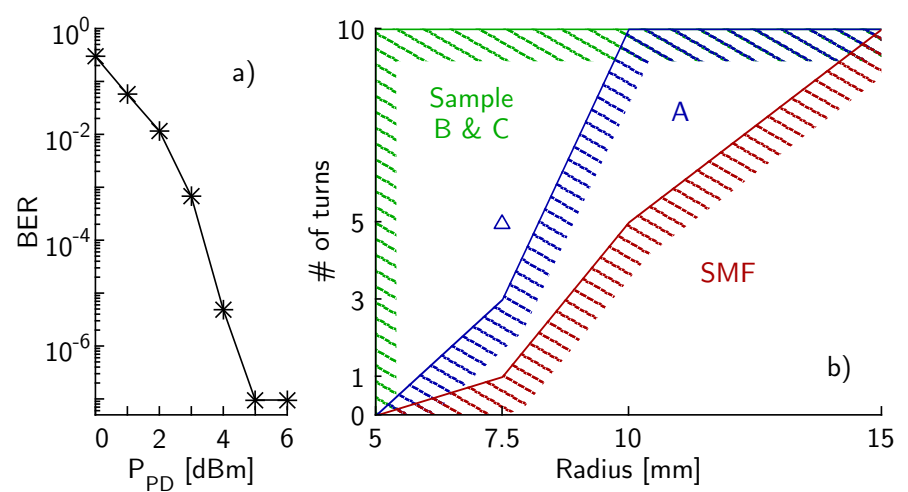

Fig. 5. a) BER vs $P_{P D}$ at $2.5 \mathrm{Gbit} / \mathrm{s}$ without bending, b) Allowable radii and numbers of turns for a system performance with BER $<10^{-6}$ at $2.5 \mathrm{Gbit} / \mathrm{s}$ $\left(\triangle: \mathrm{BER}=2.5 \cdot 10^{-6}\right.$ for 5 turns @ $7.5 \mathrm{~mm}$ with sample A)

BIF rather than whether or not BIF will be included for the last stretch of fiber in the on-site and antenna installation.

\section{CONCLUSIONS}

We assessed the performance of a W-band hybrid fiberwireless link with $70 \mathrm{~m}$ wireless and $15 \mathrm{~km}$ fiber transmission distance under the inclusion of $5 \mathrm{~km}$ of bend insensitive fiber (BIF), matching the scenarios for mobile fronthaul or wireless broadband access.

A selection of BIFs were verified to adhere to and actually outperform the requirements set by ITU-T G.657. With these the impact of fiber bending at radii between $5 \mathrm{~mm}$ and $15 \mathrm{~mm}$ on system performance has been analyzed and the trade-off between available power budget and required tolerance to bending has been discussed both with respect to the presented system as well as in general terms.

The observed loss difference between SMF and BIF suggests the inclusion of BIF as a key enabler for RoF solutions for next generation mobile fronthaul and wireless broadband access where fiber bending is unavoidable due to on-site and antenna installation. The demonstrated benefit of BIF is available to RoF in any frequency band and may be harnessed in combination with wavelength division multiplexing.

\section{ACKNOWLEDGMENTS}

The authors wish to thank Siklu Communication Ltd. for providing the $\mathrm{W}$-band antennas.

This work was partly funded by the DFF FTP mmWSPRAWL and EC IPHOBAC-NG projects. L. Cavalcante thanks the Brazilian government for supporting his research through the Science without Borders program.

\section{REFERENCES}

[1] M. García Larrodé, A. M. J. Koonen, J. J. Vegas Olmos, G. J. Rijckenberg, L. Dang Bao, and I. Niemegeers, "Transparent transport of wireless communication signals in radio-over-fibre systems," in Proc. 10th Eur. Conf. on Netw. and Opt. Comm., London, Jul. 2005, pp. 8390.

[2] J. E. Mitchell, "Integrated wireless backhaul over optical access networks," J. Lightw. Technol., vol. 32, no. 20, pp. 3373-3382, Oct. 2014.

[3] M. Morant, A. Macho, and R. Llorente, "Optical fronthaul of LTEadvanced MIMO by spatial multiplexing in multicore fiber," in Proc. OFC 2015, Los Angeles, Mar. 2015, paper W1F.6.

[4] K.-i. Kitayama, T. Kuri, J. J. Vegas Olmos, and H. Toda, "Fiber-wireless networks and radio-over-fibre technique," in Proc. CLEO/QELS 2008, San Jose, May 2008, paper CThR4.

[5] T. Pfeiffer, "Next generation mobile fronthaul architectures," in Proc. OFC 2015, Los Angeles, Mar. 2015, paper M2J.7.

[6] N. Shibata, T. Tashiro, S. Kuwano, N. Yuki, J. Terada, and A. Otaka, "Mobile front-haul employing ethernet-based TDM-PON system for small cells," in Proc. OFC 2015, Los Angeles, Mar. 2015, paper M2J.1.

[7] A. Lebedev, J. J. Vegas Olmos, X. Pang, S. Forchhammer, and I. Tafur Monroy, "Demonstration and comparison study for V- and W-band realtime high-definition video delivery in diverse fiber-wireless infrastructure," Fiber and Integrated Optics, vol. 32, no. 2, pp. 93-104, Mar. 2013.

[8] S. Koenig et al., "100 Gbit/s wireless link with mm-wave photonics," in Proc. OFC 2013, Anaheim, 2013, paper PDP5B.4.

[9] C. Lim, A. Nirmalathas, M. Bakaul, K.-L. Lee, D. Novak, and R. Waterhouse, "Mitigation strategy for transmission impairments in millimeterwave radio-over-fiber networks," J. Opt. Netw., vol. 8, no. 2, pp. 201214, Feb. 2009.

[10] D. Z. Chen, W. R. Belben, J. B. Gallup, C. Mazzali, P. Dainese, and T. Rhyne, "Requirements for bend insensitive fibers for Verizon's FiOS and FTTH applications," in Proc. OFC/NFOEC 2008, San Diego, Feb. 2008, paper NTuC2. 